\title{
Smog as a Trigger to Engage Sustainable Behavior of Young Generations
}

\author{
Nittaya Wongtada ${ }^{1, *}$ and Chirawan Chaisuwan ${ }^{2}$ \\ ${ }^{I}$ National Institute of Development Administration, Thailand \\ ${ }^{2}$ Chiangmai University, Thailand
}

\begin{abstract}
.
This study investigates toxic haze as a trigger in increasing eco-friendly behavior. A hazardous smog occurred in Chiang Mai, Thailand during January - April, 2019 provided a good opportunity to exam the connection between this incident and sustainable behavior. The theory of planned behavior and the Fogg's behavior model were employed as the foundation in observing this phenomena. The online survey was used to collect the data from university students. The result indicates that the smog influences the young to step up their proenvironmental behavior. However, there are two groups based on their main rational for the behavior. The first group takes such action is because the smog impacts them severely, and they believe in the connection between the smog and other environmental problems. For the second group, the impact of smog is not as important as imitating the peer's green behavior.
\end{abstract}

Keywords: sustainability, smog, trigger, behavior change, green behavior 


\title{
International Conference on Advanced Research in MANAGEMENT, ECONOMICS AND ACCOUNTING
}

\author{
5-7 September, 2019
}

\author{
Barcelona, spain
}

$\mathrm{MEA}_{\mathrm{E}}$

MANAGEMENT, ECONOMICS \& ACCOUNTING CONFERENCE

\section{Introduction}

Our unsustainable consumption patterns have led to many negative consequences, including air pollution, drastic climate change, massive waste accumulation, and poor human health (European Environment Agency, 2012). The awareness of environmental destruction caused by unstainable habits and expression of pro-environmental attitudes do not guarantee that individuals will act accordingly because other reasons take precedence over ecointentions and beliefs (Cagle \& Hotton, 2017). While numerous barriers inhibit environmentally sustainable behavior, several attempts and interventions aimed at promoting sustainable behaviors as attractive and socially acceptable, emphasizing the negative consequence of unsustainable behavior on our lifestyles or livelihoods, and creating venues in which individuals can express their concern and convince others to protect our ecology can break these obstacles (Morris et al., 2012). One of these interventions is based on the concept of "moment of transition" as a trigger for behavior change (Cummins, 2014). Sudden and intense air pollution could trigger for a behavioral change to protect the environment since the extreme concentration of air pollutants has a detrimental effect on human health (Cowie et al., 2015). Facing health threats from smog pollution motivates individuals to adopt new behaviors to protect themselves and their family (Bana et al., 2017), such as wearing anti-PM masks and using air purifiers. Many people are willing to pay more for cleaner energy and to adopt a sustainable lifestyle for better quality air (Chin et al., 2019).

Based on the premise in positive spillover effect, engaging in one eco-behavior could lead to the adoption of other pro-environmental related behaviors (Penz et al., 2019; Thøgersen, 1999) and strengthen self-perceptions as green consumers (Lauren et al., 2017). However, the result of a meta-analysis of Maki et al. (2019) yielded a different conclusion, indicating that the adoption of one eco-friendly behavior does not lead to more behaviors (Maki et al., 2019). Thus, the causal relationships underlying the spillover effect still need further investigation (Nilsson et al., 2017).

\section{Purpose and objective}

The study on the spillover effect from smog is limited. We found only one study by Chin et al. (2019), which concluded that some segments of the population are willing to pay for environmental protection. Whether this willingness translates into actual behavior and enhances individuals' willingness to engage in eco-friendly behavior for clean air is unknown. A situation in Chiang Mai, Thailand, offers an opportunity to observe this trigger effect on actual behavior. This haze occurred from January to April 2019 from both man-made and natural fires at the end of the dry season, which were much more severe compared to previous years due to no rain and little humidity (Promchertchoo, 2019). Residents were advised to stay indoors, and every district in the province had to establish clean air safe zones as relief centers for residents (Chiang Mai One, 2019). Students protested in front of their universities, demanding serious action on air pollution (Prachatai, 2019). 


\title{
International Conference on Advanced Research in MANAGEMENT, ECONOMICS AND ACCOUNTING
}

\author{
5-7 September, 2019
}

Barcelona, spain

$\mathrm{M}_{\mathrm{E}} \mathrm{A}$

MANAGEMENT, ECONOMICS \& ACCOUNTING CONFERENCE

Therefore, the objective of this paper was to study the potential of smog as a trigger encouraging more environmentally friendly behaviors, especially among university students. This paper starts with describing theoretical foundations guiding our research process, followed by the literature review to support our hypothesis, data collection method, data analysis, and conclusions.

\section{Research model}

The theory of planned behavior (TPB) and the Fogg behavior model (FBM) were employed to form this study's research model. The TPB developed by Azjen (1991) has been used in many studies to examine the phenomena of environmentally sustainable behavior (Isa et al., 2017). It proposes that an individual's attitude, subject norm, and perceived behavioral control influence intention which, in turn, impact behavior (Tölkes \& Butzmann, 2018). The FBM has been used to study triggers for behavior change to promote and maintain patients' health and lifelong well-being (Guo et al., 2016). This model focuses on the three influencing factors, which are motivation, ability, and triggers to create targeted behavior change (Stephens, 2014). A trigger is a prompt to remind individuals to perform the targeted behavior. It should be related to the desired behavior change and must occur simultaneously with both ability and motivation (Selvefors et al., 2011).

Our research model combined these two concepts. The factors related to FBM, including trigger, motivation, and ability, are hypothesized to have a direct effect on behavior. Ability represents the perceived behavioral control. All of these factors affect green behavior directly. Based on the TPB, environmental concern attitude, social norm, and perceived behavioral control are hypothesized to affect the intention to conserve the environment, which in turn influences green behavior. Since we were interested in the direct effect of these determinants on the behavior, we added the direct influences of these factors on the behavior to the model. Furthermore, we considered EC and SN as moderating variables between trigger, motivation, and behavior. ${ }^{1}$

\section{Literature and hypothesis development}

\subsection{Environmental concern attitude}

Environmental concern attitude (ECA) is defined as an individual's awareness of environmental problems leading to his/her desire to alleviate them (Kaufmann et al., 2012). ECA has been found to be an important determinant of eco-friendly behavior, such as purchasing green products (Groening et al., 2018); recycling (Jekria \& Daud, 2016); and bicycling (Souzaa, et al., 2014). Individuals who already adopt some pro-environmental behaviors are more likely to increase their sustainability effort by adopting other behaviors (Dietrich, 2013). Thus, living in the lingering hazy air condition might cause individuals who

\footnotetext{
${ }^{1}$ The diagram of the research model is available upon request.
} 


\section{International Conference on Advanced Research in MANAGEMENT, ECONOMICS AND ACCOUNTING}

\section{5-7 September, 2019 \\ Barcelona, spain}

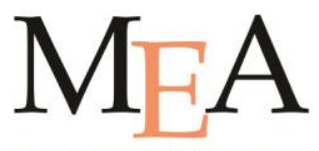

MANAGEMENT, ECONOMICS \& ACCOUNTING CONFERENCE

are concerned about the environment to increase their pro-environmental behavior in hope to be part of the solution. Based on these arguments, we formally hypothesized that:

H1: When experiencing toxic haze, individuals with higher environmental concern attitude are more likely to escalate their pro-environmental behaviors.

\subsection{Social norm}

Social norm $(\mathrm{SN})$ refers to particular behavioral patterns in which an individual engages based on the expectation of relevant peers, such as family members, friends, and inner circles (Ru et al., 2019). SN has been found to have a positive effect on the likelihood of consumers to become concerned about ecology (Poškus, 2016; Kormos et al., 2015). When students in Luxembourg believed that their family, parents, and friends perform pro-environmental behaviors, they were more willing to engage in these behaviors (Leeuw et al., 2014). At the peak of severe polluted air problem, good Samaritans distributed facemasks in public areas, raised funds to buy air purifiers for families in need, and called for overthrowing the local governor from being unable to resolve the problem (The Nation, 2019; Inkey, 2019). Evidence from Chiang Mai, Thailand, shows that people congregate who want to do good deeds into social groups. Hence, the following hypothesis tested the effect of this group on further simulating the environmental concern among young people:

H2. Social norms positively affect young people's behavior in protecting the environment.

\subsection{Perceived behavioral control}

Perceived behavioral control (PBC) refers an individual's perception of being confident in performing a task which could be easy or hard to accomplish depending on his/her existing resources and opportunities (Ajzen \& Madden, 1986). Therefore, PBC is operationalized as both perceived difficulty to perform and the perceived ability to control, both of which strongly predict intention as well as behavior (Mancha \& Yoder, 2015). In addition to being used to study sustainable behavior, PBC has been used as a determinant of behavior and intention in the smog context. If individuals believe that practices adopted to combat the toxic haze are difficult or inconvenient (Shi et al., 2017) or feel that they have no control over environmental problems, they will not become part of the solution (Chin et al., 2019). Thus, from the above rationales, the third hypothesis can be developed:

H3. Perceived behavioral control positively affects young people's engagement in sustainable behavior.

\subsection{Influence}

Personal experience with aggravating health problems from exposure to air pollution is a crucial determinant in urging individuals to alter their habit to avoid such negative effects (Semenza, et al., 2008; Zhou \& Jerrett, 2014). When individuals perceive that hazardous air pollution affects them slightly, they may only intend to take preventive action. However, when the incident affects them adversely or harms them, they move from intention to actual 


\title{
International Conference on Advanced Research in MANAGEMENT, ECONOMICS AND ACCOUNTING
}

\author{
5-7 September, 2019
}

Barcelona, spain

$\mathrm{M}_{\mathrm{E}} \mathrm{A}$

MANAGEMENT, ECONOMICS \& ACCOUNTING CONFERENCE

preventive action (Madaniyazi et al., 2015). Those who have extensive information of atmospheric pollutants and associated health risk are more likely to see the incident as an unacceptable threat and thus intend to alleviate this problem (Bana et al., 2017; Marquit, 2008). The effectiveness of smog as a trigger for behavior change is based on fear appeals which can, in turn, affect attitude, intentions, and behaviors (Tannenbaum et al., 2015). Therefore, those who view air pollution as an unacceptable risk for their health, have a preexisting inclination on perceived concern for the environment, and are surrounded by peers who pay attention to sustainability are likely to adopt other environmental protection behaviors beyond those relevant to only the smog. Thus, the following hypotheses are proposed.

H4a. Higher perceived seriousness of the negative effect of smog will increase individuals' engagement in more environmental protection behavior.

H4b: Environmental concern attitude and social norm moderate the effect of smog as the trigger of sustainability behavior.

\subsection{Connection}

Undertaking environmentally conscious behaviors in one domain could have positive effects on other behaviors in different domains (Thøgersen \& Crompton, 2009). For example, a spillover effect from recycling to packaging waste was found in a Danish adult sample (Thøgersen, 1999). The most important thing about triggers is appropriate timing, i.e., triggers need to be introduced when the user is most receptive to specific behavior. Individuals who have experienced respiratory illness are more likely to become engaged in the protection of the atmosphere and in improving air quality (Chin et al., 2019). The experience with haze may act as a trigger in engaging in eco-friendly behavior (Ateneo, 2013), especially if the causes which turn the sky brown are believed to be a part of sustainable problems. Based on these arguments, the following hypotheses are proposed.

H5a: A higher perceived connection between the existence of smog and the environmental degradation will increase individuals' engagement in additional environmental protection behaviors.

H5b: Prior environmental concern attitude and perceived social norm will mediate the effect of the perceived connection between the smog and environmental problems on the engagement of sustainable behavior.

\section{Methodology}

\subsection{Data Collection}

The survey contains four sets of questions assessing a) constructs of the TPB (environmentally concern attitude, social norm, and perceived behavioral control); b) constructs of the FBM (trigger, motivation, and ability); c) sustainable intention and behavior; and d) respondents' demographic. Since our study intended to measure the existing ECA, SN, 


\title{
International Conference on Advanced Research in MANAGEMENT, ECONOMICS AND ACCOUNTING
}

\author{
5-7 September, 2019
}

\author{
Barcelona, spain
}

$\mathrm{M}_{\mathrm{E}} \mathrm{A}$

MANAGEMENT, ECONOMICS \& ACCOUNTING CONFERENCE

and $\mathrm{PBC}$ of respondents prior to the smog, we used available scales found in the literature (e.g., Coelho et al., 2017; Dunlap et al.,2000; Junior et al.,2015; Ru et al., 2019). These preexisting scales were translated from English to Thai by one of the researchers and were crosschecked by another researcher. Subjects rated their agreement with these statements (items) on a 5-point scale ranging from 1 to 5 .

Except the ability, which was defined to be the same as PBC of the TPB, other determinants conceptualized in the FBM are IMPACT, which defines a trigger for behavior change as the consequence of the effect of smog on an individual, and LINK, which is the perceived connection between the smog and environmental problems. Since no scales to measure these determinants were available, items to assess these scales were generated from the information available in the local media and interviewing local experts. All items for these two factors as well as those for intention and actual behavior were measured on a 5point scale ranging from the highest intensity (5) to the lowest intensity (1). The questionnaire was pre-tested on a sample of 30 students from a university in Chiang Mai. The result showed positive correlations among these factors.

Next, the data was collected using an online survey method administered during May-June of 2019 to new groups of students by sending an invitation to participate, without any compensation, to various chat rooms of a local university.

\subsection{Sample}

The total sample in this study was 240 . The respondents were aged between 18- 33 years. Most of them were young ( $97 \%$ of the respondents were in the 18 to 23 years old group) and female (75\%). Close to $90 \%$ of subjects were affected by the smog at a high to a very high level. The typical effects of the smog are poor visibility, breathing difficulty, irritated eyes, having a fever, and coughing. In sum, most participants in this survey were highly affected by the past smog incident, and the effect was materialized tangibly.

\section{Results}

\subsection{Assessment of reliability and validity}

Prior to hypothesis testing, the assessment of the convergent validity, discriminant validity, and reliability of measures was performed based on the recommendation by Hair et al. (2010) (see Table 1). ${ }^{2}$ The principal component analysis with varimax rotation was used to assess the convergent validity of all scales. During this process, items with low factor loadings were eliminated and those with the loadings greater than .7 were retained. Values of average variance extracted (AVE), which measures the explained variance of the construct, were greater than .5. Thus, convergent validity was confirmed. Next, the discriminant validity was established by comparing the variance captured by a construct with its variance shared with

${ }^{2}$ The information on the assessment of the reliability and validity of factors from the TPB is available upon request. 


\section{International Conference on Advanced Research in MANAGEMENT, ECONOMICS AND ACCOUNTING}

\section{5-7 September, 2019}

\author{
Barcelona, spain
}

$\mathrm{M}_{\mathrm{E}} \mathrm{A}$

MANAGEMENT, ECONOMICS \& ACCOUNTING CONFERENCE

other constructs. We found that the construct's square root of the AVE was higher compared to the correlation of this construct with other constructs. Finally, Cronbach's coefficient alpha and composite reliability scores were used to assess the reliability of constructs. The alpha values ranging from .720 to .905 and composite reliability scores varying from .835 to .925 were greater than the acceptable minimum threshold of .7. Therefore, all constructs in our research models reached an acceptable level of reliability.

Table 1: Independent Variables from the FB Model and Behavior

\begin{tabular}{|c|c|c|c|c|}
\hline Code & Description & Loading & Mean & SD \\
\hline \multicolumn{5}{|c|}{ Impact $(\alpha=0.720, C R=.835$, Variance extracted $=55.867 \%, A V E=.745)$} \\
\hline IMPACT1 & Negative impact on my health and my family members. & 0.728 & 4.692 & 0.522 \\
\hline IMPACT2 & Negative impacts on the health of my friends and acquaintances. & 0.806 & 4.608 & 0.522 \\
\hline IMPACT4 & Negative effects on long term health. & 0.758 & 4.763 & 0.473 \\
\hline IMPACT5 & Difficulties in doing daily tasks. & 0.692 & 4.550 & 0.638 \\
\hline \multicolumn{5}{|c|}{ Link $(\alpha=0.786, C R=.861$, Variance extracted $=54.335 \%, A V E=0.543)$} \\
\hline LINK4 & Smog contaminates rivers. & 0.750 & 4.188 & 0.809 \\
\hline LINK6 & Smog contaminates soil. & 0.799 & 4.088 & 0.894 \\
\hline LINK7 & Forest fires kill animals. & 0.731 & 4.592 & 0.634 \\
\hline LINK8 & Chemical from burning in smog. & 0.699 & 4.454 & 0.713 \\
\hline LINK9 & Fire reduces diversity & 0.701 & 4.654 & 0.601 \\
\hline \multicolumn{5}{|c|}{ Behavior $(\alpha=0.816, C R=.869$, Variance extracted $=58.567 \%$; AVE $=0.572$ ) } \\
\hline ACT2 & Reuse product containers. & 0.769 & 4.275 & 0.743 \\
\hline АCT3 & Encourage friends and family to recycle. & 0.833 & 4.046 & 0.819 \\
\hline ACT6 & Recycle cardboard, paper and paper made products. & 0.753 & 4.346 & 0.733 \\
\hline ACT7 & Reuse water. & 0.710 & 3.771 & 0.986 \\
\hline ACT10 & Buy products made or packaged with recycled materials. & 0.710 & 4.108 & 0.856 \\
\hline \multicolumn{5}{|c|}{ Intent $(\alpha=0.861, C R=.898$, Variance extracted $=59.585 \%, A V E=0.596)$} \\
\hline INTENT1 & I intend to preserve the environment more. & 0.744 & 4.329 & 0.617 \\
\hline INTENT2 & $\begin{array}{l}\text { I intend to reduce carbon emissions to save the earth's } \\
\text { atmosphere. }\end{array}$ & 0.742 & 4.204 & 0.735 \\
\hline INTENT3 & I intend to participate in environmentally friendly activities. & 0.728 & 4.067 & 0.795 \\
\hline INTENT4 & I intend to stop the action that causes the loss of natural resources. & 0.797 & 4.317 & 0.720 \\
\hline INTENT5 & I will convince others To protect the environment. & 0.771 & 4.129 & 0.841 \\
\hline INTENT6 & $\begin{array}{l}\text { The smog causes me to be more concerned about the } \\
\text { environment. }\end{array}$ & 0.709 & 4.583 & 0.587 \\
\hline INTENT7 & I would like to be more eco-friendly after encountering the smog. & 0.798 & 4.479 & 0.647 \\
\hline
\end{tabular}

\subsection{Hypothesis testing}

Age was the only demographic factor that correlated with eco-friendly behavior; thus, it was included as an independent variable to minimize the threat of confounding variables. Prior to our hypothesis testing, the items representing a specific construct were averaged. The independent variable (IMPACT and LINK) and the moderator variables (ECA and SN) were 


\section{International Conference on Advanced Research in MANAGEMENT, ECONOMICS AND ACCOUNTING}

\section{5-7 September, 2019}

\author{
Barcelona, spain
}

$\mathrm{M}_{\mathrm{E}} \mathrm{A}$

MANAGEMENT, ECONOMICS \& ACCOUNTING CONFERENCE

mean-centered to reduce nonessential collinearity (Cohen et al., 2003). Subsequently, variables (IMPACT*ECA, IMPACT*SN, LINK*ECA, and LINK*SN) were derived by multiplying a moderator (ECA and SN) with a criterion variable (IMPACT and LINK) to test for interactive effects. Finally, the relationship between the determinants specified in our research model and the increase in sustainable behavior as the criterion variable was tested by employing ordinary least squares (OLS) regression procedures.

The results of four regression models (M1, M2, M3, and M4) testing the relationship hypothesized in the model are presented in Table 3. M1 tested the effect of FBM (IMPACT, LINK, and PBC) factors on sustainable behavior. M2 included factors from the TPB as predictors (EC, PBC, SN, and INTENT). M3 combined variables from both the FBM model and TPB. M4 added the interaction between factors from FBM and TPB model.

The multicollinearity might not an issue in our data because the largest value of variance inflation factor (VIF) was only 2.024, which did not exceed the acceptable value of 10, with tolerance value being less than 0.10 (Hair et al., 2010). Regression equations were statistically significant for all models. $\mathrm{R}^{2}$ for M1 which contained the variables from the FBM was .324 , supporting $\mathrm{H} 3, \mathrm{H} 4 \mathrm{a}$, and $\mathrm{H} 5 \mathrm{a}$ that these variables have a positive effect on sustainable behaviors adopted as a consequence of experiencing the smog. PBC factor was the most important, with the standardized coefficient of .440 and statistical significance at a $99 \%$ confidence level. In M 2, the TPB variables also have positive effects on sustainable behavior with $\mathrm{R}^{2}$ of .378. Thus, H1, H2, and H3 were supported. Again, PBC emerged as the most important variable of sustainable behavior (.295 with statistical significance at a $99 \%$ confidence level), followed by INTENT, SN, and EC.

Table 2: Regression Results with Sustainable Behavior from Smog as Dependent Variable

\begin{tabular}{lcccc}
\hline & FBM & TPB & FMB+TMB & Interact \\
\hline Gender & M1 & M2 & M3 & M4 \\
\hline LINK & $0.122^{* *}$ & $0.100^{*}$ & 0.083 & 0.081 \\
\hline IMPACT & $0.142^{* *}$ & & $0.102^{*}$ & 0.091 \\
\hline PBC & $0.131^{* *}$ & & 0.040 & 0.055 \\
\hline EC & $0.440^{* * *}$ & $0.295^{* * *}$ & $0.278^{* * *}$ & $0.291^{* * *}$ \\
\hline SN & & $0.100^{*}$ & 0.070 & 0.076 \\
\hline INTENT & & $0.194^{* * *}$ & $0.177^{* * *}$ & $0.162^{* *}$ \\
\hline LINK_EC & & $0.235^{* * *}$ & $0.205^{* * *}$ & $0.204^{* *}$ \\
\hline LINK_SN & & & & -0.036 \\
\hline IMPACT_EC & & & & -0.033 \\
\hline IMPACT_SN & & & 0.389 & 0.043 \\
\hline R2 & & 0.378 & 0.392 \\
\hline R2 Change & 0.335 & 0.364 & 0.371 & 0.362 \\
\hline Adjusted R2 & & & & \\
\hline
\end{tabular}




\title{
International Conference on Advanced Research in MANAGEMENT, ECONOMICS AND ACCOUNTING
}

\author{
5-7 September, 2019
}

\author{
Barcelona, spain
}

$\mathrm{MEA}_{\mathrm{E}}$

MANAGEMENT, ECONOMICS \& ACCOUNTING CONFERENCE

The comparison of the variables in the FBM and TPB model revealed that TPB variables had stronger positive effects on green behavior compared to the FBM variables. In M3, all TPB variables except EC had a positive influence on the behavior of interest while only LINK from the FBM was statistically significant at 90\%. This indicates the TPB model is more relevant to environmental conservation. Moreover, by adding FBM variables to the TPB model (M3 model), $\mathrm{R}^{2}$ change was .053 , suggesting that the behavior change could occur if individuals see the link between the smog and other environmental problems, even though the effect is relatively small. When observing the moderating effect of EC and SN in M4, the interactions between LINK and EC; LINK and SN; IMPACT and EC; and IMPACT and SN were not statistically significant. Therefore, $\mathrm{H} 4 \mathrm{~b}$ and $\mathrm{H} 5 \mathrm{~b}$ were not supported. ${ }^{3}$

\section{Conclusion}

\subsection{Discussion}

The findings of this study extend our understanding of the effect of a sudden environmental threat on individuals' behaviors in conserving the ecology. Both the smog's threat to health and its interference on their daily life activities, as well as the perception of the connection between air pollution and environmental problems, influence increased engagement of young people in green behavior. Their perceived behavior effectiveness is the most important determinant of actual behavior, which is consistent with the previous studies indicating that perceived behavior effectiveness is the most important determinant of proenvironmental behavior (e.g., De Leeuw et al., 2015; Ru et al., 2018; Lizin et al., 2017).

When observing only determinants from the theory of planned behavior, those who were already concerned about environment problems felt the presence of social norm on sustainable practices and believed that their eco-friendly actions will increase their activities in conserving the environment while facing intense air pollution. In fact, the influence of these TPB factors on the green action was stronger compared to those of the Fogg's behavior model. In a combined model (M3), social norm, perceived behavioral control, and intention to protect the environment were statistically significant while the only significant variable from the Fogg's behavior model was the perceived connection between the smog and the environmental problems. That is, when the young are strongly influenced by their peers to increase their eco-friendly behavior and, at the same time, they somewhat see the link between the smog and other environmental problems, the belief in their ability to protect the environment as well as their intention to do so will motivate them to engage in sustainable behaviors.

\footnotetext{
${ }^{3}$ Additional analyses were performed to test the theoretical suitability of our data. By using our data, the constructs in the TPB demonstrate the relationship patterns as postulated in this theory. The results of the analyses are available upon request.
} 


\title{
International Conference on Advanced Research in MANAGEMENT, ECONOMICS AND ACCOUNTING
}

\section{5-7 September, 2019}

\author{
Barcelona, spain
}

$\mathrm{MEA}_{\mathrm{E}}$

MANAGEMENT, ECONOMICS \& ACCOUNTING CONFERENCE

\subsection{Managerial implications}

This study focused on whether a sudden environmental problem, such as polluted and toxic air, could convince the youths to increase their engagement in a more sustainable lifestyle. We identified two groups of young individuals. The toxic smog was a rude awakening for the first group to start to reuse, recycle, favor package made from recycled material, and convince others to act pro-environmentally. They believe that the smog phenomenon is part of environmental decay. To gain attention and to convince this group to do more for the environment, activities that promote environmental conservation behavior should be launched during the peak of a toxic haze. The message should emphasize the consequence of smog for one's well-being and the connection between smog and other environmental problems. Combining two effects of smog, i.e., the smog can harm one's well-being and the smog leads other environment problems, increased the young people's intention to protect the environment.

The second group contained two sub-groups: those who are already concerned about the environment and thus actively engage in eco-friendly behavior without paying attention to the health effect or the connection between smog and environmental problems, and those who are mainly influenced by their eco-friendly peers and see some association between the smog and sustainable problems. Both subgroups are likely to behave pro-environmentally based on their perceived ability to protect the environment and their intention to engage in conservation behavior. The message sent to the first sub-group could be simpler since the information on the harmfulness of the smog on health can be omitted. A hint on the association between the haze and environmental deterioration or just being in the harmful smog situation could convince them to do more for the environment. To translate the intention of individuals in all groups to actual behavior, they must be convinced that environmental conservation is under their control. If not, they will not act at all.

\subsection{Limitations and future research}

This study has some limitations. The data were collected from students attending social science departments in a university, and the response to our survey was based on a voluntary basis. This led to the overrepresentation of female respondents. In addition, our models explained less than $40 \%$ of the underlying reasons for the young to increase their environmental behaviors. Other determinants for eco-friendly behaviors should be included in future studies, such as socio-economic profile, general attitude propensity, trust in green promoters, and eco-friendly activities (Wongtada, 2019). The sustainability of the behavioral change as a result of the toxic smog incident is still questionable. Although the study found that this incident increased young people's engagement in eco-friendly behavior, whether the young will continue this behavior after the smog problem vanishes is unknown. A longitudinal study should be conducted to determine whether these newly acquired green behaviors habituated. 


\title{
International Conference on Advanced Research in MANAGEMENT, ECONOMICS AND ACCOUNTING
}

\section{5-7 September, 2019}

\author{
Barcelona, spain
}

$\mathrm{MEA}_{\mathrm{E}}$

MANAGEMENT, ECONOMICS \& ACCOUNTING CONFERENCE

\section{References}

[1] European Environment Agency. (March 5, 2012). Unsustainable consumption - the mother of all environmental issues? Available: https://www.eea.europa.eu/highlights/unsustainable-consumption-2013-the-mother

[2] Ajzen, I. (1991). "The theory of planned behavior," Organizational Behavior and Human Decision Processes, vol. 50(2), pp. 179-211.

[3] Ajzen, I., and Madden, T. J. (1986). "Prediction of goal directed behavior: Attitudes, intentions, and perceived behavioral control," Journal of Experimental Social Psychology, vol. 22, pp. 453-474.

[4] Ateneo, S. D. (2013). Pro-environmental spillover in consumer behavior: Existence and drivers, Venice, Italy: Università Ca' Foscari Venezia.

[5] Bana, J., Zhou, L., Zhanga, Y., Andersonc, G. B. and Lia, T. (2017). "The health policy implications of individual adaptive behavior responses to smog pollution in urban China," Environment International, vol. 106, pp. 144-152.

[6] Cagle, L. and Hotton, V. (2017). Behavior Change for Sustainability: Northwest Earth Institute's Approach, Portland: Northwest Earth Institute.

[7] Chiang Mai One. (March 9, 2019). Chiang Mai establishes clean air safe zones for smog relief. Available: https://chiangmaione.com/chiang-mai-establishes-clean-air-safe-zonesfor-smog-relief-3164

[8] Chin, Y. S., Pretto, L. D., Thuppil, V. and Ashfold, M. J. (2019). "Public awareness and support for environmental protection-A focus on air pollution in peninsular Malaysia," PLoS ONE, vol. 14(3): e0212206.

[9] Coelho, F., Pereira, M. C., Cruz, L., Simoes, P. and Barata, E. (2017). "Affect and the adoption of pro-environmental behaviour: A structural model," Journal of Environmental Psychology, vol. 54, pp. 127-138.

[10] Cowie, H., Crawford, J., Davis, A. and Steinle, S. (2015). Air Quality, Health, Wellbeing and Behaviour, Scotland: Institute of Occupational Medicine.

[11]Cummins, J. (April 9, 2014,). Ten things we learnt about behaviour change and sustainability. Available: https://www.theguardian.com/sustainable-business/behaviouralinsights/behaviour-change-sustainability-debate

[12]Dietrich, H. L. (2013). The Role of Emotion in Environmental Decision Making, Dissertation, University of Nebraska, Lincoln, Nebraska.

[13]Dunlap, R. E., Liere, K. D., Mertig, A. G. and Jones, R. E. (2000). "Measuring endorsement of the new ecological paradigm: A revised NEP scale," Journal of Social Issues, vol. 56(3), pp. 425-442. 


\section{International Conference on Advanced Research in MANAGEMENT, ECONOMICS AND ACCOUNTING}

\section{5-7 September, 2019}

\section{Barcelona, spain}

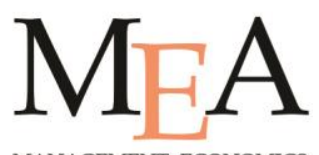

MANAGEMENT, ECONOMICS

\& ACCOUNTING CONFERENCE

[14] Groening, C., Sarkis, J. and Zhu, Q. (2018). "Green marketing consumer-level theory review: A compendium of applied theories and further research directions," Journal of Cleaner Production, vol. 172, pp. 1848-1866.

[15]Guo, Y., Yang, M., Hu, J. and Tao, L. (2016). "Persuasive tech in keeping chronic patients' willingness in health self-management," Advances in Energy, Environment and Materials Science, Guanghzou, China: CRC Press, pp. 769-772.

[16]Inkey, M. (April 10, 2019). Thais in the North dying for a smog solution. Available: https://www.asiatimes.com/2019/04/article/thais-in-the-north-dying-for-a-smog-solution/

[17] Isa, S. M., Lim, C. K. and Chin, P. N. (2017). "Green purchase intention of laundry detergent," Global Business and Management Research: An International Journal, vol. 9(4), pp. 128-143.

[18] Jekria, N. and Daud, S. (2016). "Environmental concern and recycling behaviour," Procedia Economics and Finance, vol. 35, pp. 667-673.

[19] Kaufmann, H. R., Panni, M. F. and Orphanidou, Y. (2012). "Factors affecting consumers' green purchase behavior: An integrated conceptual model," Amfiteatru Economic, vol. 14(31), pp. 50-69.

[20]Kormos, C., Gifford, R. and Brown, E. (2015). "The influence of descriptive social norm information on sustainable transportation behavior: A field experiment," Environment and Behavior, vol. 47(5), pp. 479-501.

[21]Lauren, N., Smith, L. D., Louis, W. R. and Dean, A. J. (2017). "Promoting spillover: How past behaviors increase environmental intentions by cueing self-perceptions," Environment and Behavior, vol. 51(3), pp. 235-258.

[22]Leeuw, A. d., Valois, P. and Seixas, R. (2014). "Understanding high school students' attitude, social norm, perceived control and beliefs to develop educational interventions on sustainable development," Procedia - Social and Behavioral Sciences, vol. 143. pp. 1200 -1209 .

[23]Lizin, S., Van Dael, M. and Passel, S. (2017). "Battery pack recycling: Behaviour change interventions derived from an integrative theory of planned behaviour study," Resources Conservation and Recycling, vol. 122, pp. 66-82.

[24] Madaniyazi, L., Nagashima, T., Guo, Y., Yu, V. and Tong, S. (2015) "Projecting fine particulate matter-related mortality in east China," Environmental Science and Technology, vol. 49(18), pp. 11141-11150.

[25]Maki, A., Carrico, A. R., Raimi, K. T., Truelove, H. B., Araujo, B. and Yeung, K. L. (2019). "Meta-analysis of pro-environmental behaviour spillover," Nature Sustainability, vol. 2, pp. 307-315.

[26] Mancha, R. M. and Yoder, C. Y. (2015). "Cultural antecedents of green behavioral intent: An environmental theory of planned behavior," Journal of Environmental Psychology, vol. 43, pp. 145-154. 


\section{International Conference on Advanced Research in MANAGEMENT, ECONOMICS AND ACCOUNTING}

\section{5-7 September, 2019}

\section{Barcelona, spain}

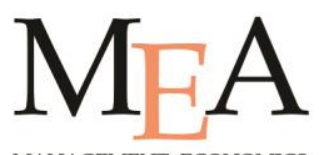

MANAGEMENT, ECONOMICS \& ACCOUNTING CONFERENCE

[27] Marquit, J. D. (2008). Threat perception as a determinanat of pro-environmental behaviors: Public involvement in air pollution. Available: https://digitalcommons.usu.edu/cgi/viewcontent.cgi?article=1187\&context=etd

[28] Morris, J., Marzano, M., Dandy, N., \& O’Brien, L. (2012). Theories and models of behaviour and behaviour change: Theories. Available: https://www.forestresearch.gov.uk/documents/1409/behaviour_review_theory.pdf.

[29] Nilsson, A., Bergquist, M. and Schultz, W. P. (2017). "Spillover effects in environmental behaviors, across time and context: A review and research agenda," Environmental Education Research, vol. 23, pp. 573-589.

[30]Penz, E., Hartl, B. and Hofmann, E. (2019). "Explaining consumer choice of low carbon footprint goods using the behavioral spillover effect in German-speaking countries," Journal of Cleaner Production, vol. 214, pp. 429-439.

[31] Poškus, M. S. (2016). "Using social norms to encourage sustainable behavior: A metaanalysis," Psichologija, vol. 53, pp. 44-58.

[32] Prachatai. (March 18, 2019, March 18). Chiang Mai joins Global Climate Strike on its most polluted day. Available: https://prachatai.com/english/node/7976

[33] Promchertchoo, P. (April 6, 2019). On the front line with the Chiang Mai firefighters battling the flames behind the world's worst air. Available: https://www.channelnewsasia.com/news/asia/thailand-chiang-mai-fire-worlds-worst-airpollution-11417294

[34]Ru, X., Qin, H. and Wang, S. (2019). "Young people's behaviour intentions towards reducing PM2.5 in China: Extending the theory of planned behaviour," Resources, Conservation \& Recycling, vol. 141, pp. 99-108.

[35] Selvefors, A., Pedersen, K. B. and Rahe, U. (2011). Design for sustainable consumption behaviour: systematising the use of behavioural intervention strategies. Proceedings of the 2011 Conference on Designing Pleasurable Products and Interfaces, Article No. 3.

[36] Semenza, J. C., Wilson, D. J., Parra, J., Bontempo, B. D., Hart, M., Sailor, D. and Georg, L. A. (2008). "Public perception and behavior change in relationship to hot weather and air pollution," Environmental Research, vol. 107(3), pp. 401-411.

[37] Shi, H., Fan, J. and Zhao, D. (2017). "Predicting household PM2.5-reduction behavior in Chinese urban areas: An integrative model of theory of planned behavior and normactivation theory," Journal of Cleaner Production. vol. 145, pp. 64-73.

[38] Souzaa, A. A., Sanches, S. P. and Ferreira, M. A. (2014). "Influence of attitudes with respect to cycling on the perception of existing barriers for using this mode of transport for commuting," Procedia - Social and Behavioral Sciences, vol. 162, pp. $111-120$.

[39] Stephens, M. (2014). Sustainable Behavior Change at Kensas State University: Applying the Fogg Behavior Model as a Community-based Social Marketing Approach Among Faculty and Staff, Master's thesis, Kansas State University, 
[40] Tannenbaum, M. B., Hepler, C., Zimmerman, R. S., Saul, L., Jacobs, U., Wilson, U. and Albarracin, C. (2015). "Appealing to fear: A meta-analysis of fear appeal effectiveness and theories," Psychological Bulletin, vol. 141(6), pp. 1178-1204.

[41] The Nation. (April 1, 2019). Good Samaritans hand out thousands of N95 face masks in smog-bound Chiang Mai. Available:

http://www.nationmultimedia.com/detail/breakingnews/30366933

[42] Thøgersen, J. (1999). "Spillover processes in the development of a sustainable consumption pattern," Journal of Economic Psychology, vol. 20(1), pp. 53-81.

[43] Thøgersen, J. and Crompton, T. (2009). "Simple and painless? The limitations of spillover in environmental campaigning," Journal of Consumer Policy, vol. 32, pp. 141163.

[44] Tölkes, C. and Butzmann, E. (2018). "Motivating pro-sustainable behavior: The potential of green events-A case-study from the Munich," Sustainability, vol. 10, 3731.

[45] Wongtada, N. (2019). "Applying consumer neuroscience to sustainable behaviors studies," Proceedings of NIDA International Business Conference 2019, Bangkok, Thailand: NIDA Business School, pp. 343-357.

[46]Zhou, Y. and Jerrett, M., (2014). "Linking exposure and health in environmental public health tracking," Environmental Research, vol. 134, 453. 